\title{
Automated Chamber for Prickle Pear Cauterization
}

\author{
Federico Hahn* and Angel Hernandez \\ IAUIA Universidad Autonoma Chapingo, Texcoco México
}

*Corresponding author: Federico Hahn, IAUIA Universidad Autonoma Chapingo, Texcoco México

\begin{abstract}
Mexico is the world largest producer of cactus pear (Opuntia spp.) and is searching for new processes that allow to export them. The fruit is rich in nutrients but is highly perishable having ambient shelf life of 9 days. Cauterization and cryo-cauterization techniques have increased shelf life to 2 and 3 months without refrigeration. An automatic system was developed to flip the fruit towards the dry-ice wall inside a chamber. A horizontal actuator pushed the container to cauterize the fruit. The entire cauterizing process for each fruit lasted 23 seconds. By exchanging the dry-ice wall every 500 fruits, a $100 \%$ cauterizer efficiency was achieved.
\end{abstract}

Keywords: Automatic Chamber; Cauterization; Prickle Pear; embedded system

\section{Introduction}

Cactus pear (Opuntia spp.) is a fruit produced in arid and semi-arid regions around the world [1]. Mexico is the world's largest producer of cactus pear (Opuntia spp.) with $79.4 \%$ of world production, and with 49,165 ha under cultivation [2]. Italy is now the world's largest exporter of cactus pear to the European Union (EU), producing about 87 thousand tons annually in Sicily, which corresponds to $96 \%$ of the total Italian harvest [3]. Cactus pear is generally consumed fresh, but is highly perishable, showing high incidence of spots and rotting after 9 days. After 20 days at ambient conditions, almost $70 \%$ of the fruit was visibly damaged [4]. By cooling prickle pears to $10^{\circ} \mathrm{C}$, shelf life increased to 6 weeks [5] Fresh cactus pear shelf life can be increased to 32 days in modified atmosphere packaging with less than $20 \mathrm{kPa} \mathrm{CO} 2$ [6]. A cauterizer cut and seal 120 pieces of fruit per hour [7]; cuts were made close to the cactus cladode at $150{ }^{\circ} \mathrm{C}$ during harvest, destroying thorns. After 2 months of storage, $78 \%$ of the pears were unspoiled. The application of uniform heat treatments has been effective in controlling postharvest diseases, but can damage the treated fruit tissue if not applied carefully. Excessive heating period may damage the fruit, while insufficient heating may leave non-sterilized surface segments [8]. Further developments of cauterizer machines by Hahn [9-12] applied heat to sliced pears. After applying a constant pressure of $100 \mathrm{kPa}$ at $200^{\circ} \mathrm{C}$ during $30 \mathrm{~s}$ to harvested cactus pears increased shelf life to 2 months, controlling effectively postharvest diseases [9]. However, heat application is expensive when many fruits are cauterized. A cryo-cauterization process used a pneumatic robotic gripper to press a cactus pear against a dry-ice wall within a thermally isolated chamber. Fruit cryocauterizing at $150 \mathrm{kPa}$ for 15 s increased shelf life to 90 days, keeping $86 \%$ of marketable fruit [11].

Automation of agriculture tasks have improved pre-harvest, harvest and post-harvest stages. Machine vision sorting of fruits presents advantages of high accuracy, precision and processing speed [13]. Non-contact detection makes grading and sorting free of mankind diseases. Fruits and vegetables produced in farms are sorted according to quality and maturity levels and decisions taken of the market it can be sent on the basis of transportation delay [14]. Post-harvesting operations require quality detection [15] and skin defects [16]. A pepper robotic harvester system [17] avoiding stem and fruit damage would be highly successful. Although food processing methods extend the shelf life of fruit and vegetable products, fresh-cut produce may lead to flavor loss, discoloration, rapid softening, and increased rate of vitamin loss [18]. Emerging smart packaging reduce losses, maintain quality, add value and extend shelf-life of agricultural produce [19]. It alerts the consumer from contamination of pathogens, pesticide residues or food degradation in food packaging products [20]. Intelligent packaging with nano sensors senses and informs the condition of the product 
to provide information about quality during transport, distribution, and storage [21]. This technology may also be used to detect adverse reactions in consumers after taking food such as gluten, peanuts and tree nuts [22]. Automation for the application of these sensors is considered a future close innovation. In this paper, an automatic system used for prickle pear cryo cauterization within a very small chamber was developed. The chamber size obeys to the rapid melting of dry-ice caused by environmental conditions. A minimum number of operations is required and the system efficiency evaluated to cauterize 120 pears per hour.

\section{Mechanism for Pear Cauterization}

The top-surface sliced prickly pear is moved within a container into the cryo-cauterized chamber (Figure 1 ) by means of a conveyor belt. This band transports the fruits in a direction parallel to the dry-ice wall where cauterization takes place. A trapezoidal metal container resembles a porcelain coffee mug and holds the prickly pear (Figure 2) whose flat base stops at the bottom. The container base is $3 \mathrm{~mm}$ thick (Figure 2) and has force sensor in between the base and the prickle pear. The system mechanism has to perform the following functions:

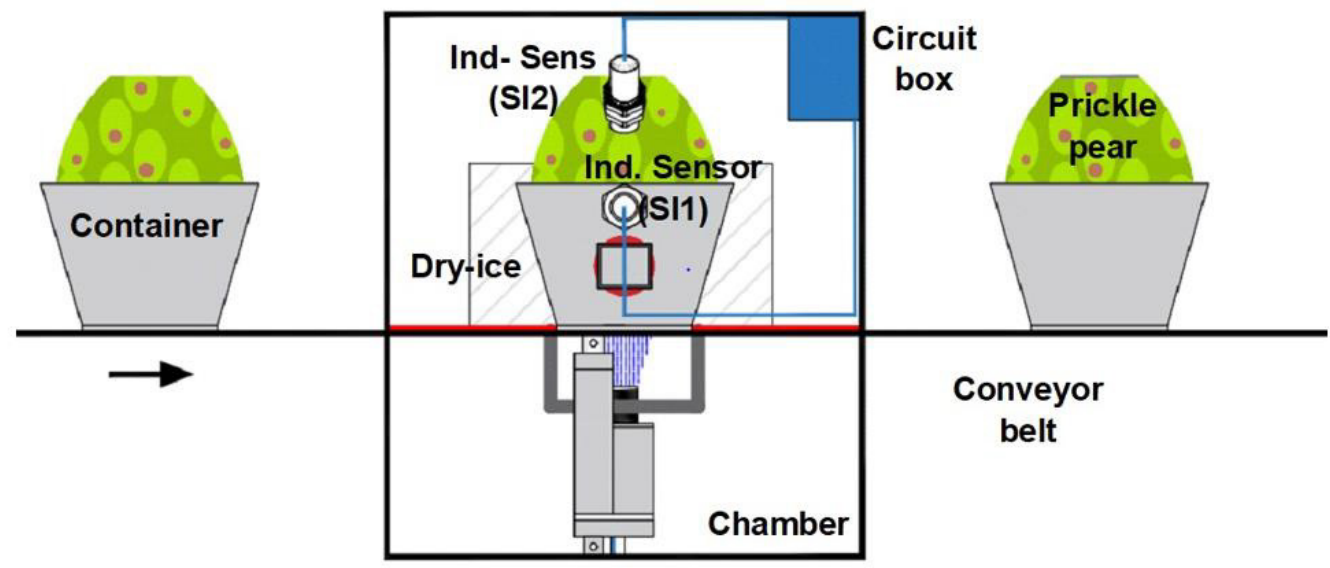

Figure 1: Prickle pear conveyor belt and cauterizer chamber.

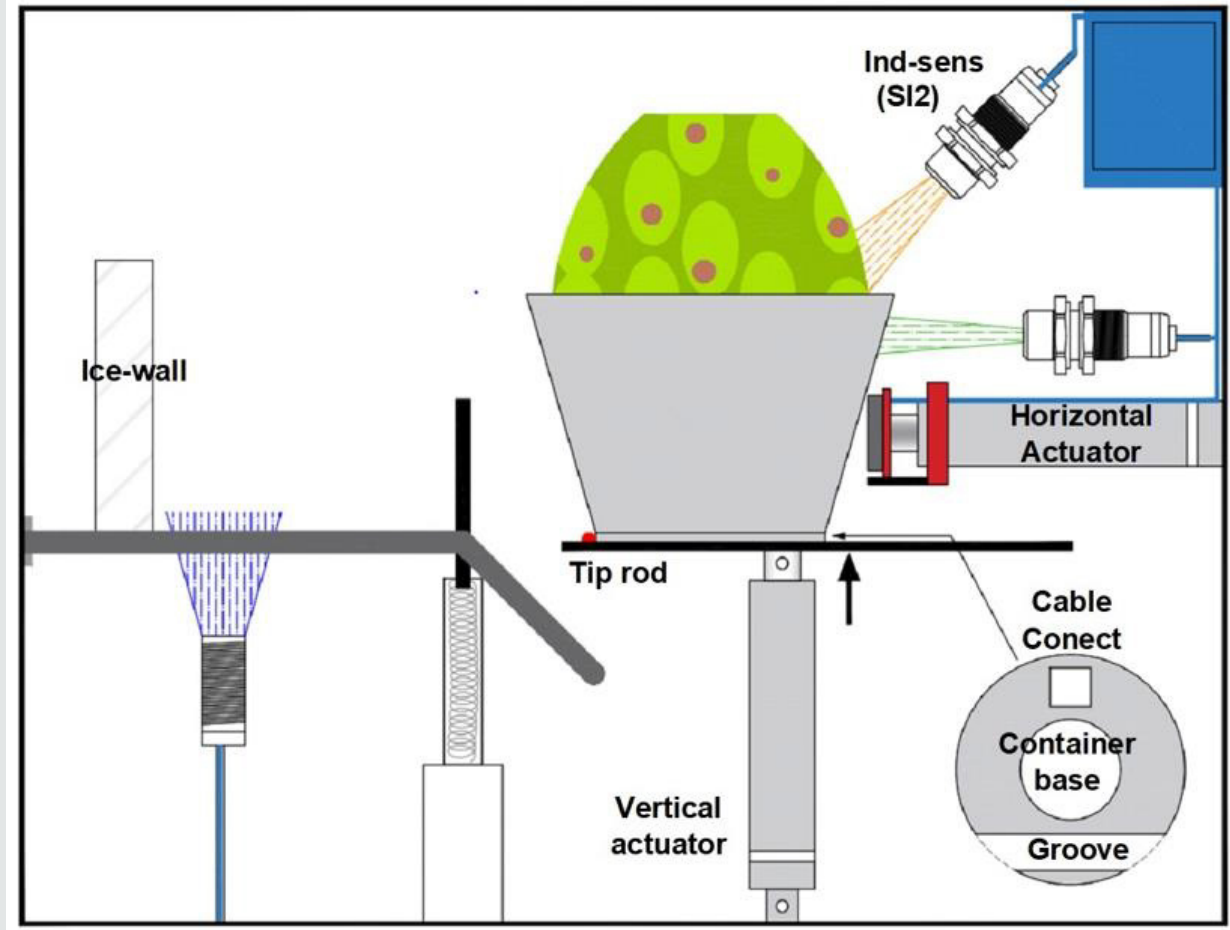

Figure 2: Bottom actuator and initial rotation operation. 
1. Detect when the prickle pear is present within the metal container.

2. Rotate it $90^{\circ}$ counterclockwise.

3. Displace it against the dry ice wall.

4. Return it and deposit it to the original band.

During the first stage, a conveyor belt transports the prickle pear to the cauterizer chamber rising the door in the left side. At the same time, it opens another door to exit the previous cauterized pear. For the second function, the mechanism used an actuator (A1) to flip the metal container (Figure 2). The linear piston or actuator (mod. LA 14, LINAK, Denmark) is characterized by its compact size being ideal for this chamber having a limited amount of space available. The aluminum actuator is used in harsh and cold environments up to $-40{ }^{\circ} \mathrm{C}$. A metal ring with a sectional groove is located at the container base (Figure 2). The lower piston plunger enters the groove and as it moves upwards, it turns the container base (Figure 3); a tip rod flips the container as the piston rises. After 45 or 50 degrees of rotation, the actuator rod gets out of the groove and the container falls by gravity. A small compression spring stops the container reaching its end point over a pair of rails (Figure 3). The third operation requires of a second electric actuator (A2) that pushes the container together with the fruit until it reaches the dry-ice wall, where it will stay pressurizing the pear for 15 seconds. Fruit moves at most $5 \mathrm{~cm}$ over two rails before it reaches the dry-ice wall. The electric actuator (mod. LA 25, LINAK, Denmark) presents a speed of $20 \mathrm{mms}^{-1}$, withstanding cold temperatures of $-25^{\circ} \mathrm{C}$.

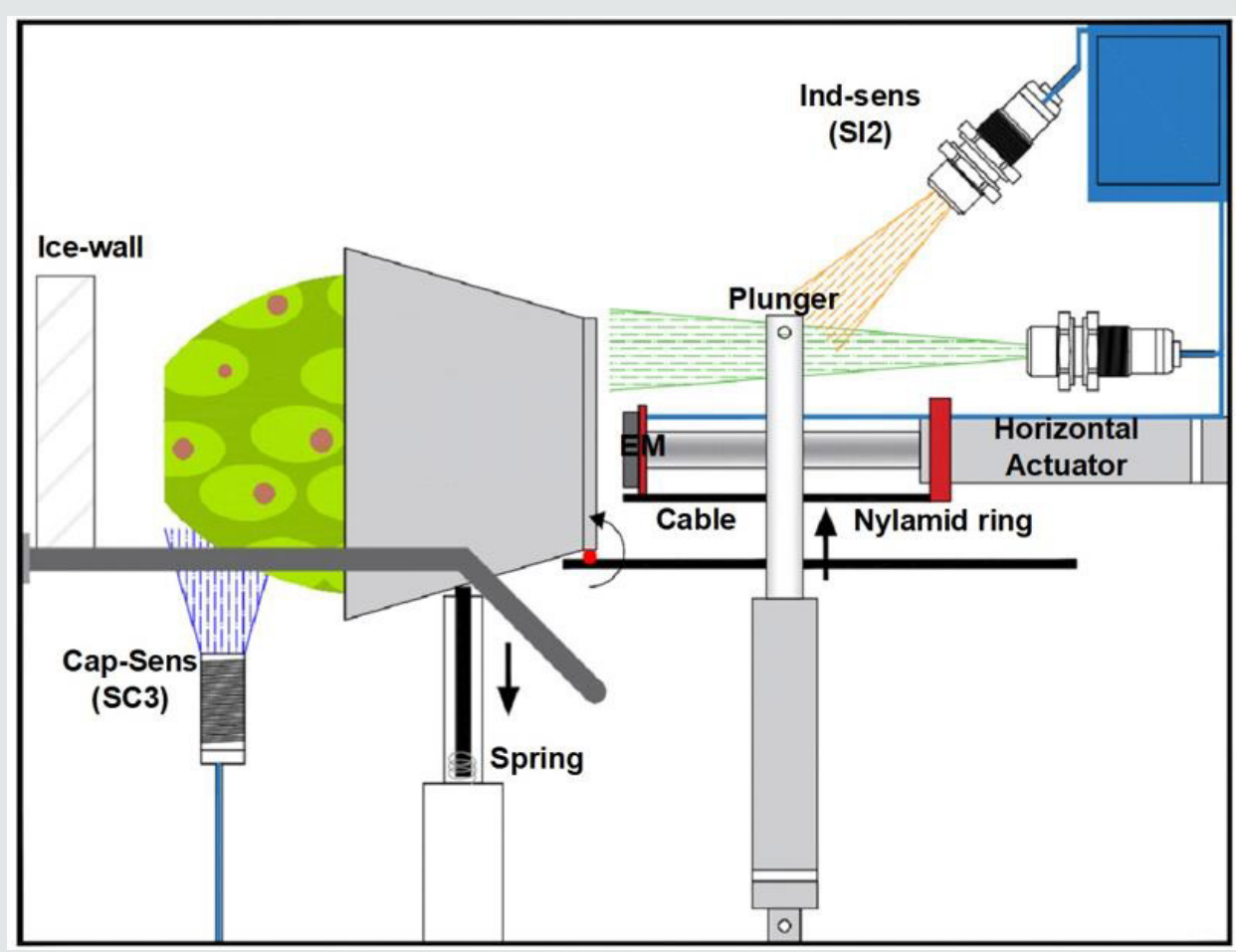

Figure 3: Ending prickle pear rotation.

The fourth operation returns the container with a 12 VDC round electromagnet mounted at the end of the piston rod. After activating the $30 \mathrm{~mm}$ diameter electromagnet, the container remained fixed and forced to return. A micro switch (MS1) was activated at the runend, and the voltage supplied to the electromagnet was interrupted releasing the container that felt to initial band position. The voltage supplied to the horizontal actuator was also cut.

\section{Electrical Automation}

Once implemented the chamber with its mechanisms, the sensors for automation were obtained. The process begins when the conveyor belt is turned on, which will enter the cauterization chamber and an inductive presence sensor (SI1) will detect when it is in the desired position. This sensor will serve to turn off the band and at the same time it will feed the actuator (A1) so that its rod moves upward, initiating the rotation of the container. The rod or plunger will come out from the container base and an inductive sensor (SI2) provides a signal to limit its travel. The container flips unto a pair of rails and a capacitive sensor (SC3) detects its presence, and its signal activates the horizontal actuator (A2). Its plunger with the electromagnet at its end pushes the fruit container towards the dry-ice wall. The force sensor (SF) starts measuring when the prickle pear touches the wall. The contact is maintained for 15 seconds and at the same time a negative voltage 
is applied for 5 seconds to the vertical actuator so that it returns to its initial position. Force sensor resistors (FSR) provide a resistance that is inversely proportional to the applied force and can measure grabbing and pressing. Flex Force sensors enable non-intrusive static and dynamic force measurements presenting better force linearity, hysteresis and temperature sensitivity than other thinfilm force sensors [23-25]. Voltage processing was done through a Wheatstone bridge having the variable flex force sensor in one arm as in the data glove [25]. The output voltage is compared and the output provided to the embedded system. At the end of the cauterizer time, the electromagnet (EM) is activated and the polarity of the horizontal actuator is reversed until it touches a micro switch (MS1). When MS1 is actuated, the electromagnet and the horizontal piston are turned-off allowing the container to fall by gravity onto the conveyor belt. The band turns on and a new cycle starts taking out of the chamber the cauterized fruit and putting in the prickly pear to be treated. Figure 4 shows the cauterizer system timing chart for automation.

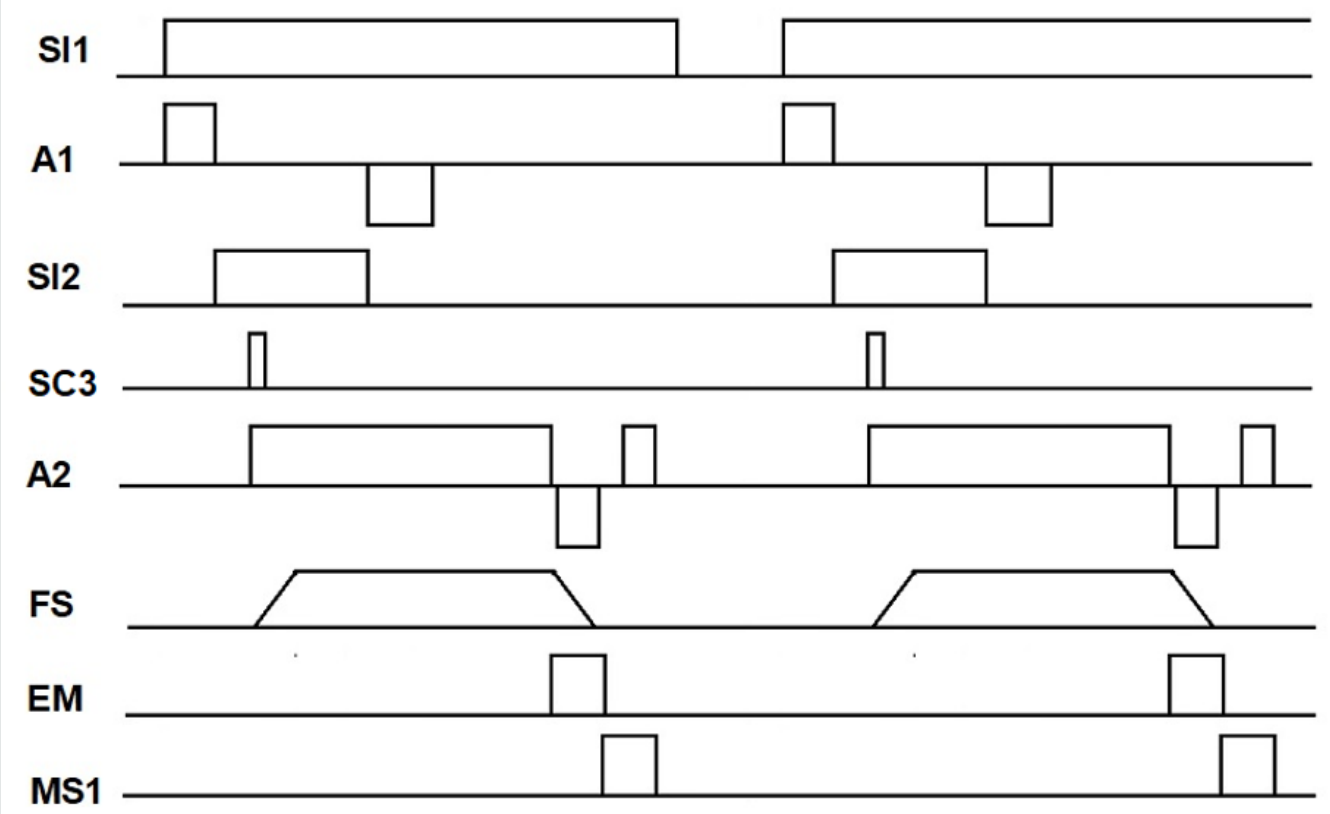

Figure 4: Automatic system time chart.

\section{Embedded System}

The control system employs only digital inputs and outputs and all the outputs were connected to port 1 of the ATM8951 microcontroller (Figure 5). Three output pins of port-1 were connected to H-Bridge 1 (P1.0, P1.1 and P1.2) and another 3 pins to H-Bridge 2 (P1.3, P1.4 and P1.5). The H-Bridge 1 and H-Bridge 2 controls the horizontal and vertical actuator motors, respectively. The three control terminals of H-Bridge 1 are enable, IN1 and IN2. If $\mathrm{H}$-Bridge 2 is selected ( $\mathrm{EN}=1)$, the actuator rod will move upwards when IN1 $=1$ and IN2 $=0$. The actuator motor stops by setting IN $1=$ IN2 $=0$, and if IN1 $=0$ and IN2 $=1$, the actuator will move the rod downwards. The horizontal actuator will move the container towards the dry-ice wall with IN1 $=1$ and IN2 $=0$. In the case of having IN1 = 0 and IN2 = 1, the actuator will return back. The H-Bridge used was MC33HB2001 (NXP Semiconductors,
Netherlands) as it can handle $10 \mathrm{~A}$ and $34 \mathrm{~V}$. A N-Channel Power MOSFET (NTP5860NL, Semiconductor Industries, USA) turned-on the electromagnet once P1.7 applied a 5-volt signal. The routine starts when the fruit is detected by the inductive detector. The signal interrupt the microcontroller turning-on the vertical actuator (Figure 5). The embedded routine starts polling and asks whether the vertical plunger has arrived to its limit position where the inductive detector (SI2 P2.0) detects it. The vertical actuator motor is stopped and checks if the pear is over the rails; the capacitor sensor will detect it (SC3 P2.3). The microcontroller moves the horizontal actuator and when the force sensor provides a $5 \mathrm{~V}$ signal, the controller provides a cauterizing timing of 15 seconds. Otherwise it waits until FS changes to 1 . After the 15 seconds, the container together with the pear returns once the electromagnet is activated by the MOSFET (pin 1.7). The controller waits until SW1=1 (P2.5) to stop the actuator. 


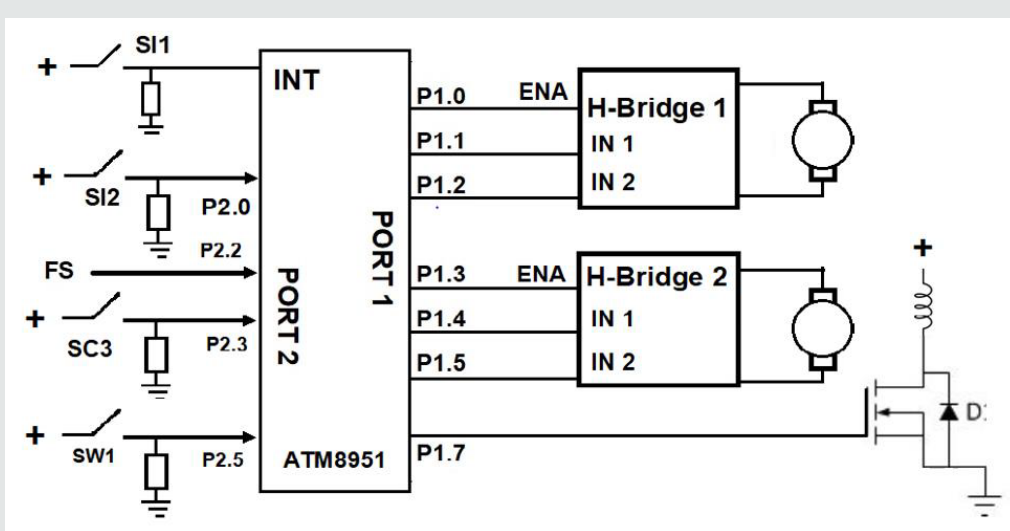

Figure 5: Embedded circuit control.

\section{Experimental Fruit Measurements}

The container diameter was fixed based on the maximum equatorial measurement of the prickle pears. Two hundred fruits (Opuntia var. Amarilla \& Cristalina) commonly grown in Mexico were harvested and weighted. Prickle pears variety "Amarilla" were lighter $96 \pm 5.3 \mathrm{~g}$ having a diameter ranging between 4.9 and $5.5 \mathrm{~cm}$. Prickle pears var "Cristalina” were heavier 197 $\pm 13.1 \mathrm{~g}$ having a diameter ranging between 5 and $5.7 \mathrm{~cm}$. Maximum fruit length was $8 \mathrm{~cm}$ for both varieties. These values agree with the study carried by Corrales and Hernandez using the same varieties [26]. Considering these values, the container was designed to be $5.5 \mathrm{~cm}$ long with a diameter of $5.7 \mathrm{~cm}$.

\section{Chamber and Mechanism Evaluation}

The total weight of the container plus the prickly pear was less than 500 grams considering that the deposit weighs 285 grams. Although smaller pistons can be employed, it was decided to work with ones already proven for use in hospitals. These actuators have motors that work at 12 or $24 \mathrm{VDC}$ and handle loads of up to $750 \mathrm{~N}$. The current obtained at 12 VDC was $200 \mathrm{~mA}$, being half that when operating at 24 VDC. Linear rod speed was the main parameter to study since it could affect container rotation and fruit stability. An experiment was carried out to determine the best operation at three different speeds $\left(25 \mathrm{mms}^{-1}, 35 \mathrm{mms}^{-1}\right.$ and $\left.45 \mathrm{mms}^{-1}\right)$. Fifty fruits within containers were rotated for each speed after lifting the container base with the actuator. The two quicker speeds used a spindle pitch of $4 \mathrm{~mm}$, while the low speed worked with a $2 \mathrm{~mm}$ pitch. Twenty-one prickly pears (42\%) felt in between the rails when the rod moved at the highest speed. As speed was reduced to $35 \mathrm{mms}^{-1}$ only $6(12 \%)$ prickly pears came out from the container. With a speed of $25 \mathrm{mms}^{-1}$ the container rotated slower and no pears were ejected from the container. The LA 25 actuator used as horizontal actuator used a 24 VDC power supply, being the current used 1.8 A during pressing against the wall and 0.9 during container horizontal displacement. The current of $1.8 \mathrm{~A}$ is obtained when a force of $1200 \mathrm{~N}$ is applied. A $9 \mathrm{~mm}$ pitch was employed and its push linear speed reached $8 \mathrm{mms}^{-1}$. The linear speed without such force is $10 \mathrm{mms}^{-1}$, so it takes 3 seconds to move the container $30 \mathrm{~mm}$.

For the final evaluation, three thousand fruits were used, which were cauterized in groups of one thousand and sliced manually in groups of twenty. The total time required to cauterize a prickly pear was 23 seconds being 15 seconds the fruit contact against the dryice wall. The vertical actuator stepped-up $50 \mathrm{~mm}$ in two seconds at a speed of $25 \mathrm{mms}^{-1}$. At that moment the prickly pear felt into the rails and after another second the horizontal actuator pushed the fruit against the cauterizing wall. Two additional seconds were required to return of the prickly pear and its repositioning on the conveyor belt. The electromagnet only worked one second out of every 20 seconds giving a $13 \%$ duty cycle which kept its magnet temperature under control; the low temperature of the chamber was also helpful to avoid heating. The efficiency of cauterization in the first 20 prickly pears was of $8 \%$, so 4 fruits were not properly cauterized. The shape of these prickle pears did not allow them to contact the flex sensor at the container end. Therefore, no reading was obtained and the cauterization timing provided by the microcontroller was null; after a minute the fruit was still inside the chamber contacting the dry-ice wall. Only prickle pears with equatorial diameters smaller than $55 \mathrm{~mm}$ were used in the first experiment with 1000 fruits. The processing of the first 1000 fruits took a little more than 500 minutes ( 4 hours and 20 minutes). An audible alarm was added to determine if there was no measurement with the force sensor. A proper $92 \%$ cauterization efficiency resulted and 80 prickly pears were not properly cauterized. The electrical connection between the container and the sliding cable for the force sensor output was not well made or it resulted in false contacts in 68 fruits; After hearing the alarm the pears were removed. The other 12 prickly pears did not make adequate contact with the dry ice due to a slightly tilted cut that came from a previous operation outside the chamber. With the other group of 1000 prickle pears, the force sensor and the external electrical contacts were removed. The period to move the horizontal actuator was increased to 18 seconds. A total of 987 prickle pears with precise cuts at the top were properly sealed 
and the last 13 fruits had problems as the dry-ice block melted, becoming thinner. As the block becomes thinner it is unable to withstand the cauterizer pressure. It is important to change the $15 \mathrm{~mm}$ thick dry-ice plate every 500 prickly pears, since at the end of the cauterization of 500 fruits it is only $3 \mathrm{~mm}$ thick. Another one thousand pears were introduced to the chamber, but the dry-ice plate was exchanged twice; a proper cauterizer efficiency of $100 \%$ was obtained. This result indicates that three systems can work in parallel, which would triple the amount of cauterized prickly pears without reducing the dry-ice wall thickness so quickly.

\section{Conclusion}

This work shows an automatic system for cauterizing prickle pears which will extend the shelf life up to 3 months. The automatic equipment can cauterize 1000 fruits in 4 and a half hours, being each fruit processed in 23 seconds. The dry-ice block melts as every time a fruit enters the chamber it heats it up. As it melts it becomes thinner and it will not be able to withstand the cauterizer pressure. The embedded system used to cauterize fruits was simple and the flex force sensor was removed as it generates some contact problems; as well signal connections should be wireless. Both actuators worked precisely under $-5^{\circ} \mathrm{C}$ harsh conditions.

\section{Acknowledgements}

I would like to acknowledge all the technical staff of the University that helped to build the prototype.

\section{References}

1. Shedbalkar U, Adki V, Jadhav J, Bapat V (2010) Opuntia and other cacti: applications and biotechnological insights. Tropical Plant Biology 3 : 136-150.

2. Añorve J, Aquino E, Mercado E (2006) Effect of controlled atmosphere on the preservation of minimally processed cactus pears. Acta Horticulturae 728: 211-216

3. Timpanaro G, Foti V (2014) The structural characteristics, economic performance and prospects for the Italian cactus pear industry. Journal Professional Association Cactus Development 16: 32-50.

4. Granata G, Sidoti A (2002) Survey of diseases discovered on Opuntia ficus-indica in producer countries. Acta Horticulturae 581: 231-237.

5. Schirra M, Inglese P, La-Mantia T (1999) Quality of cactus pear [Opuntia ficus-indica (L.) Mill.] fruit in relation to ripening time, $\mathrm{CaCl}_{2}$ pre-harvest sprays and storage conditions. Scientia Horticulturae 81(4): 425-436.

6. Guevara J, Yahia E, Brito de la Fuente E, Biserka S (2003) Effects of elevated concentrations of $\mathrm{CO}_{2}$ in modified atmosphere packaging on the quality of prickly pear cactus stems (Opuntia spp.). Postharvest Biology and Technology 29(2): 167-176.

7. Hahn F (2009) Cactus pear cauterizer increases shelf life without cooling processes. Computers and Electronics in Agriculture 65: 1-6.
8. Lurie S (2006) The effect of high temperature treatments on quality of fruits and vegetables. Acta Horticulturae 712(712): 165-174

9. Hahn F, Cruz J, Barrientos A, Perez R, Valle S (2016) Optimal pressure and temperature parameters for prickly pear cauterization and infrared imaging detection for proper sealing. Journal of Food Engineering 191: 131-138.

10. Hahn F (2016) Equipo industrial para la cauterización de tunas. Industrial equipment to cauterize prickle pears México.

11. Hahn F, Valle S, Jenkins T (2019) Robotic cactus pear cryocauterization increases storage life. Postharvest Biology and Technology 147: 132138.

12. Hahn F (2018) Proceso y equipo industrial para cauterizar la superficie afectada por el corte en tunas, después de su cosecha. Process and industrial equipment to cauterize prickle pear sliced surface after harvest México.

13. Jarimopas B, Jaisin N (2008) An experimental Machine Vision system for sorting sweet Tamarind. Journal of Food Engineering 89(3): 291 - 297.

14. Nandi C, Tudu B, Koley C (2012) An automated machine vision based system for fruit sorting and grading. Proceedings of the International Conference on Sensing Technology pp.195-200.

15. Liu Y, Sun X, Zhang H, Aiguo O (2010) Nondestructive measurement of internal quality of Nanfeng mandarin fruit by charge coupled device near infrared spectroscopy. Computer Electronics Agriculture 71S: S10-S14.

16. Adamiak A, Zdunek A, Kurenda A, Rutkowski K (2012) Application of the biospeckle method for monitoring bull's eye rot development and quality changes of apples subjected to various storage methodspreliminary Studies. Sensors 12(3): 3215-3227.

17. Hemming J, Bac C, Tuijl B (2011) CROPS project deliverable 5.1: Report with design objectives and requirements for sweet-pepper harvesting. Wageningen UR Greenhouse Horticulture Netherlands.

18. Artes P, Gomez P, Artes F (2013) Unit processing operations in the freshcut horticultural products industry: Quality and safety preservation. Food Quality, Safety and Technology Austria p. 35-52.

19. Opara U, Mditshwa A (2013) A review on the role of packaging in securing food system: Adding value to food products and reducing losses and waste. African Journal of Agricultural Research 8(22): 2621-2630.

20. Rhim J, Park H, Ha C (2013) Bio-nanocomposites for food packaging applications. Prog Polymer Science 38(s 10-11): 1629-1652.

21. Yam K, Takhistov P, Miltz J (2005) Intelligent packaging: concepts and applications. Journal of Food Science 70(1): R1-R10.

22.Sanjib K, Jatindra K (2014) Nanotechnology in Food Processing. Introduction to Advanced Food Process Engineering pp. 315-342.

23. Ashruf C (2002) Thin flexible pressure sensors. Sensor Review 22(5): 322-327.

24. Wettels N, Santos V, Johansson R, Loeb G (2008) Biomimetic tactile sensor array Advanced Robotics 22: 829-849.

25. Tarchanidis K, Lygouras J (2003) Data glove with a force sensor. IEEE Transactions on Instrumentation and Measurement 52(3): 984-989.

26. Corrales J, Hernandez J (2005) Cambios en la calidad postcosecha de variedades de tuna con y sin semilla. Revista Fitotecnia Mexicana 2(1): 9-16. 
(C) (i) This work is licensed under Creative Commons Attribution 4.0 License

To Submit Your Article Click Here: Submit Article

DOI: 10.32474/ARME.2021.03.000152

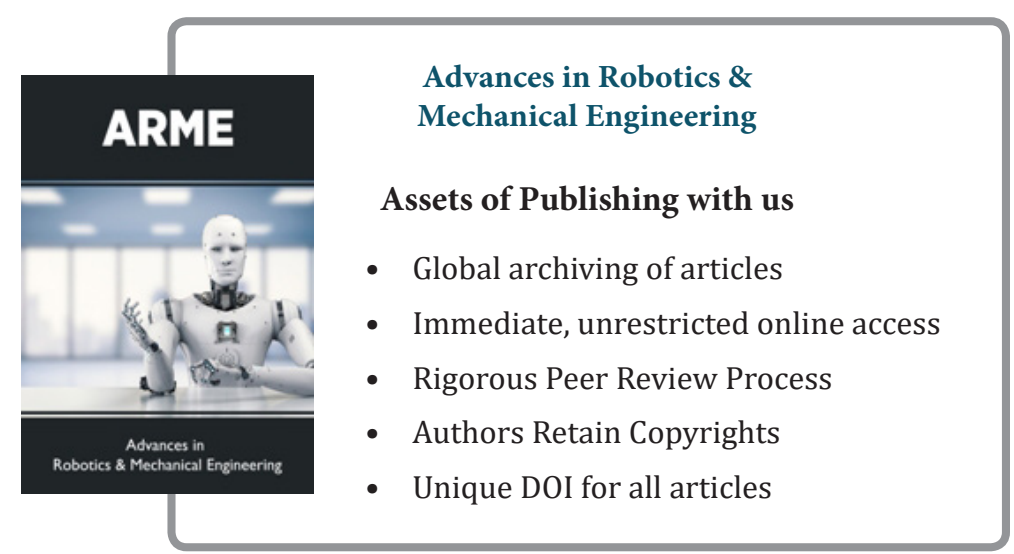

